NASA Technical Memorandum 101434

\title{
Predictions of Airfoil Aerodynamic Performance Degradation Due to Icing
}

Robert J. Shaw, Mark G. Potapczuk, and Colin S. Bidwell

Lewis Research Center

Cleveland, Ohio

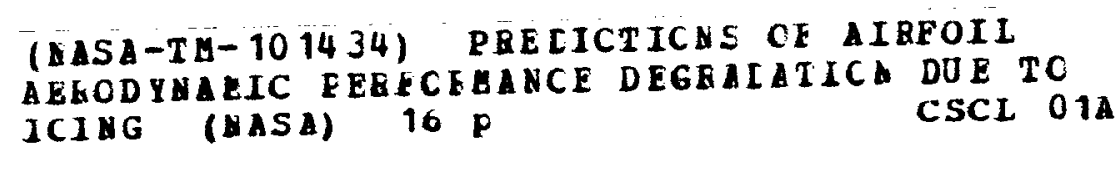
$189-13 \overline{4} \widehat{12}$
Unclas
G3/02 0183405

Prepared for the

Fourth Symposium on Numerical and Physical Aspects of Aerodynamic Flows sponsored by California State University at Long Beach

Long Beach, California, January 16-19, 1989 
PREDICTIONS OF AIRFOIL AERODYNAMIC PERFORMANCE DEGRADATION DUE TO ICING

Robert J. Shaw, Mark G. Potapczuk, and Colin S. Bidweil

National Aeronautics and Space Administration

Lewis Research Center

Cleveland, Ohio 44135

\section{Abstract}

An overview of NASA's ongoing efforts to develop an airfoil icing analysis capability is discussed. An indication is given to the approaches being followed to calculate (1) the water droplet trajectories past the airfoil, (2) the bulldup of ice on the airfoil, and ( 3 ) the if resultant changes in aerodynamic performance due
if to the leading edge ice accretion. Examples are ' given of current code capabilities/limitations through comparisons of predictions with experimental data gathered in various calibration/validation experiments. A brief discussion of future efforts to extend the analysis to handle three-dimensional components is included.

\section{List of Symbols}

c airfoil chord

$C_{d}$ airfoil drag coefficient

c) airfoil lift coefficient

$\mathrm{Cmc} / 4$ airfoil moment coefficient

$C_{p}$ airfoil surface pressure coefficient

LWC icing cloud liquid water content

MVD icing cloud volume median droplet diameter

5 surface distance

$T_{\infty} \quad$ freestream total temperature

U local velocity

Ue edge velocity

$v_{\infty} \quad$ freestrean velocity

$x, y$ coordinates

$x_{t r}$ transition location

a airfoil angle-of-attack

B local water droplet collection efficiency

$\theta$ angular position

\section{Introduction}

One of the major elements of the NASA AIrcraft Icing Research Program is the development and validation of a series of mutually compatible computer codes which predict the details of an aircraft icing encounter. These codes once validated can be used for:

(1) Making preliminary design studies to ascertain component sensitivity to icing.
(2) Making performance predictions of proposed ice protection systems.

(3) Conducting computer based certification/ qualification studies to reduce the amount of required icing flight testing.

(4) Providing more accurate and realistic icing effects inputs for use in flight training simulators.

Figure $I$ is a flowchart which shows the many codes required to form such an icing analysis methodology as well as the codes currently under development by NASA. Reference 1 provides an overview of the icing analysis activities (analytical and experimental) underway.

The purpose of this paper is to review the progress on one element of the overall activity. namely the unprotected airfoil icing problem. Simply stated, the problem being addressed is to develop/validate computer codes which predict (1) the bulldup of ice on an unprotected airfoil and (2) the resultant derodynamic degradation levels due to that ice accretion shape. A validated airfoil icing analysis capability is felt to be the core capability for the overall icing analysis methodology shown in Fig. 1 . This airfoil icing analysis capability will be extended to handle three-dimensional components (e.g.. swept wings) and eventually complete aircraft configurations.

Figures 2 and 3 pictorially show the problem being addressed. A wing section of constant chord was placed in the NASA Lewis Icing Research Tunnel (IRT) and subjected to specified icing conditions (cloud liquid water content, average droplet diameter. free stream temperature and icing time) and aerodynamic conditions (velocity and angle-ofatta(k). The figure shows the resultant leading edge ice accretion in overall and closeup views. The rough irregular nature of the ice accretion should be noted.

Figure 3 shows in a generalized fashion the decrease in aerodynamic performance which can occur due to leading edge ice accretions; namely:

(1) An increase in wing section drag even at low angles-of-attack

(2) A decambering of the airfoil due to a thickened upper surface boundary layer

(3) A reduction in $C_{1 \max }$ and, premature stall due to separation of the airfoil upper surface boundary layer.

For any given airfoll geometry, the ice accretion can change dramatically in cross sectional shape as the environmental and aerodynamic parameters are varied. The level of severity of aerodynamic performance degradation will also vary 


\section{DPPANA PRE \\ OF POOR QUALTY}

significantly depending on the ice accretion characteristics as well as the basic airfoil performance characteristics.

Previous experimental studies have determined many of the key aspects of the airfoil icing problem. These aspects must be adequately modeled/ predicted in any alrfoil icing analysis me thodology (Fig. 4). While an airfoil ice accretion shape is typically small relative to the airfoil size (usually only a few percent chord in maximum dimension), its effect on the airfoil flowfield and thus the airfoll aerodynamic performance can be profound. The ice accretion shape is highly rough and irregular (as the closeup portion of Fig. 2 suggests). The roughness elements (size and distribution) are much different than the classical sand grain elements used in wind tunnel test programs over the years. The developing boundary layers on both the suction and pressure sides will tend to separate in the near vicinity of the ice accretion. At lower angles-of-attack, boundary layer reattachment from either or both surfaces will usually occur aft of the ice accretion, but the reattached viscous layer $(s)$ will be thickened and distorted. As the angle-of-attack is changed, the relative sizes of the suction and pressure surface separationreattachment zones will change. In particular as the angle-of-attack is increased, the suction sur face zone will grow in size until no reattachment occurs and airfoil stall results. Airfoil stall can occur several degrees below the stall angle observed for clean airfoils. The increase in dray occurring at the lower angles-of-attack is due to thickened, distorted boundary layers which develop over the airfoll aft of the leading edge ice accretion.

The mutually compatible computer models required to form an airfoil icing analysis capability are shown in $\mathrm{Fig}$. 5 . The overall approach to the problem will first be discussed and then each module will be discussed.

\section{Overall Approach}

As Fig. 5 indicates, a potential flow analysis is first performed to determine the inviscid flowfield around the clean airfoil. The trajectory module computes the paths of water droplets past the alrfoll and determines the rate at which droplets are impacting the airfoil surface at each point. This represents the local rate of water deposition on the airfoil.

The ice accretion module calculates the local rate of ice growth around the airfoil. The distribution of lce growth rates around the airfoll surface allows an lce shape to be predicted once a user specified time increment (called the time step) is selected. This time increment is chosen such that the effect of ice buildup on airfoll flowfield and thus droplet trajectory paths is thought to be minimal.

Once the ice shape is calculated, then a viscous flowfleld calculation is performed using the predicted ice shape if aerodynamic performance degradation levels are required.

If it is desired to continue to computationally accrete lce on the airfoil, then the looping process is repeated for as many time increments as is required to reach the overall icing encounter time. Each successive loop begins with a potential flowfield analysis of the airfoil with the leading edge modifled by the ice accretion computed from the previous step(s).

It is highly desirable for the separate inviscid and viscous flow analyses to be combined (i.e. replace the inviscid analysis step with the viscous analysis). However, a significant increase in computational resources currently is required to complete the viscous analys is (minutes on a (ray XMP) versus that required to complete the inviscid analysis (minutes on an IBM 370 ). Obviously as the $i$ ce shape grows in size and dominates the airfoil leading edge flowfield, viscous effects (boundary layer separation/reattachment) will become so dominant that the simplified inviscid analysis will no longer be appropriate.

The following sections will look at the modules in more detail.

\section{Inviscid Flowfield/Droplet Trajectories}

The flowfield about the airfoil (clean and iced) is calculated using a potential flow analysis - a second order panel code developed by Hess-Smith. Flowfield information - individual panel geometry and source/vorticity strengths - is passed to the trajectory module to allow calculation of the water droplet paths past the airfoli. The droplet equations of motion are integrated using a predictor-corrector scheme optimized for stiff systems of equations. Flowfield velocity values at various points on the airfoil surface required for integration of the equations of motion are determined by summing the individual contributions of all panels.

The accuracy of the trajectory analysis is being assessed by comparison with an experimenta? droplet impingement data base being developed jointly by NASA and the FAA. 2 Selected comparisons are shown in Fig. 6 for data gathered on a clean cylinder model as well as on an "iced" cylinder model. The figure al so shows droplet collection efficiency predictions made using a Navier-Stokes flowfield analys is in place of the Hess-Smith potential code. Both sets of predictions generally agree well with the clean cylinder data although the tails of the collection eff $i-$ ciency curves are broader for the data than for the predictions. This was expected as the calculations were made for a single droplet size (the average diameter) while the actual droplet cloud had a spectrum of sizes.

The agreement is not as good for the "iced" cylinder. espectally in the so-called horn regions. Experimental measurements of the surface pressure distribution about the ice shape indicated the boundary layer separated just aft of each horn. Since potential flow analyses do not account for separation, the local velocities in the vicinity of each horn are predicted to be larger than actually exist. This inadequacy in the flowfield modeling was felt to be reason for the overprediction of the collection efficiency levels in the vicinity of the horns and led to the trajectory calculations using the NavierStokes analysis. Suprisingly the inclusion of the viscous effects did not significantly decrease the collection efficiency levels near the horn. 
The reason for this discrepancy is not known but it may suggest some inaccuracy in the experimental approach. The surprising level of agreement in collection efficiency predictions using the panel and Navier-Stokes codes for both the clean and iced cylinders suggests the panel code calculations can provide reasonable estimates of the collection efficiency distributions for clean and iced airfoils.

As already stated, in the long term it is desirable to replace the inviscid analysis with a viscous analysis in the airfoil icing andiysis methodology to properly account for boundary layer separation - reattachment.

\section{Ice Accretion}

In spite of the fact that aircraft icing has been studied since the 1920's, the understanding of the governing physical processes of ice accretion is limited. Consequently, lce shapes are predicted using a control volume approach as depicted in Fig. 7. Mass and energy balance equations are formulated accounting for the effects shown in the figure. The equations are solved to determine the fraction of incoming water which freezes in each control volume. Any water which does not freeze in a control volume is assumed to flow back to the immediately aft control volume (so called runback water). Required inputs from the flowfield/trajectory analysis include the collection efficiency and surface velocity distributions.

Figure 8 shows representative comparisons of predicted versus measured ice shapes. In each case, the ice shape prediction is compared to an ice shape grown in the NASA IRT. The colder temperature condtion resulted in a rime ice condition while the warmer temperature resulted in a glaze ice accretion. (Glaze ice shapes tend to have horn characteristics which result in large levels of aerodynamic degradation). Al so note that the figure shows the predicted ice shape(s) were grown in time steps, each of 30 seconds duration. The agreement in predicted versus measured ice shape for both cases is judged to be acceptable. Currently efforts are underway to make a large number of lce shape comparisons with not only data gathered in many icing ground tests facilities but also with natural icing flight data. This extensive set of comparisons will serve as a code calibration/validation effort for the ice accretion analysis.

A significant input to the ice accretion calculation procedure has been shown to be the convective heat transfer coefficient $(h)$ distribution. Currently, the $h$ distribution is calculated using an integral boundary layer approach described by White 3 and Kays and Crawford. 4 An experimental heat transfer coefficient data base has been acquired ${ }^{5}$ to evaluate the adequacy of the predic tion approach, and a comparison is shown in Fig. 9. The cylinder fee shape shown is the same as the shape used in the trajectory impingement studies. The major disagreement is seen to be in the vicinity of the horn and downstream of the horn. The disagreement is attributed to the potential flow prediction of surface velocity distribution not accounting for the observed boundary layer separation.
As already indicated (Fig. 2), Ice accretion shapes can exhibit a large degree of surface roughness and an attempt has been made to account for this effect in the ice accretion analysis. A distribution of sand grain roughness is input and the heat transfer rates are increased according to the predictions of the integral boundary layer approach. The heat transfer data base acquired included testing ice shapes to which sand grains of known size were affixed. One prediction/experimental comparison of this rough surface heat transfer is shown in Fig. 10. The same general remarks can be made as were already made for the smooth surface ice shape. Also a comparison of Figs. 9 and 10 reveals that the increase in measured heat transfer due to roughness was predicted reasonably well by the integral boundary layer routine.

Experimental efforts are currently being conducted to acquire additional heat transfer data for both smooth and rough surface airfoils for comparison with predicted levels. The data base includes measurements of the effect of free stream turbulence on heat transfer levels. Also, efforts are underway to determine more accurate ways of characterizing the surface roughness than the simple sand grain element approach currently used.

In order to improve the physical understanding of the ice accretion process, close-up photographs and movies have been taken of the icing process on an airfoil. 6 such data has been acquired both in artificial and natural icing conditions. These photographic results suggest that some of the assumptions contained in the control volume model of ice accretion may be in error. In particular, the model allows for continuous flow of water on the surface. That is, any water not frozen in a control volume is allowed to run back to the adjacent control volume. The photographic evidence suggests that after an initial transient, surface water (if it exists) does not appear to move. A multizone model that has been proposed to account for this discrepancy is depicted in Fig. 11. Surface water is allowed to run in zone $A$ which would be characterized as a smooth region. Zone $C$ would be a transition region which would have a varying roughness while zone $B$ would be a region which would have no runback. The transition region (zone C) would move toward the stagnation point as the icing time increases and thus zone $A$ would decrease in size with icing time. Currently, the position of zone $C$ is determined empirically but it is most desirable to be able to relate it to the governing physics. Currently this multizone model is being added to the ice accretion module to evaluate the resultant improvement in ice shape predictions.

Also, efforts are underway to model some of the other aspects of the ice accretion process noted in the photographic data that are not included in current ice accretion analysis. These effects include droplet impact and possible splashing and water beading into large droplets. Additional efforts (experimental and analytical) are underway to better understand the water film dynamics effects for inclusion into the ice accretion modeling. It is hoped that inclusion of these physical effects in the ice accretion analysis will contribute to improved ice shape predictions. 


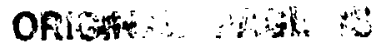 OF POOR QUALTY}

\section{Aerodynamic Performance}

Two analysis codes are being applied to predict airfoil aerodynamic performance degradation due to ice accretion: (1) a Reynolds averaged Navier Stokes code (ARC2O) and (2) an interactive boundary layer code (IBL). 8 Both of these codes were originally developed to handle "clean" geometries and are being extended to handle iced airfolls. In order to properly evaluate these codes, a comprehensive validation data base is required. The initial approach being followed to acquire such a data base is summarized in $\mathrm{Fig} .12$. A NACAOO12 airfoll model was modified to have a leading edge with an idealized ice shape. This ice shape was chosen to have the gross cross sectional features of an ice shape grown in the IRT but to have a well defined surface description to allow inputting into the flow analysis codes. Detailed surface pressure distributions and wake survey probe measurements allowed global force and moment performance to be documented. Boundary layer velocity profiles on both suction and pressure surfaces were acquired using both pitot tubes and single element hot film probes. The profile measurements were concentrated in the separationreattachment zones. Flow visualization data was acquired to complement the quantitative data base. Reference 9 provides more details of the experimental program.

Figure 13 summarlzes the predictions of the $A R C 2 D$ and IBL codes when compared to the experimental data base already discussed. The predictions of both codes for lift and drag coefficient levels for the lower angles-of-attack agree well with the data. At the higher angles-of-attack, the IBL code tended to underpredict the measured drag levels. At these higher angles-of-attack, the ARC2D code predicted that an unsteady flowfield existed (i.e.. no steady solution was reached when the code was run in the time accurate mode). The ARC2D results for those higher angles-of-attack were determined by averaging the surface pressure distributions over one cycle and then calculating the resultant $\mathrm{C}_{1}, \mathrm{Cmc}_{4}$, and $C_{d}$ values. The IBL code also had some difficulty achieving a converged solution at these conditions but due to the formulation of the interactive boundary layer approach, no such averaging procedure was possible.

While the global comparisons of code predictions of $C_{l}$ and $C_{d}$ versus experimental measurements yielded generally favorable results. significant differences did occur when comparisons were made of surface pressure distributions and velocity profiles. Both codes tend to predict upper surface boundary-layer reattachment to occur prior to the measured reattachment points.

Figure 14 shows some selected velocity profile comparisons. Note that both codes predicted separated profiles at $X / C=0.005$ which were significantly different than the measured profile. The ARC2D code predicted reattachment to have occurred at station 0.043 but the experimental profile suggested that reattachment had not occurred. Also. the predicted static pressure distributions showed much greater negative pressure peaks near separation than were observed to occur in the experiment.
Three possible sources of these discrepancies were noted and are currently being investigated: (1) ice shape definltion/flowfield grid generation, (2) boundary layer transition, and (3) turbulence modelling.

Figure 15 shows the results of a grid definition study conducted with the ARC2D code using an ice accretion shape predicted using the ice accretion analysis module already discussed. Note the ice shape is not smooth and well defined like the idealized ice shape already discussed. Two NASA Ames developed grid generation codes were used in the study: a Poison solution approach (GRAPE) and a hyperbolic generation approach (HYPGRID). The curvilinear body fitted grids were 253 (along the surface) $\times 64$ (into the flowfield).

The GRAPE code was used with points uniformly distributed around the surface while the HYPGRID code was used with both uniform distributions and densely packed leading edge distributions. Also, the HYPGRID code was run with more points placed closer to the airfoil surface so as to capture more details of the growth of the viscous layers. A comparison of the ARC2D predictions on a $C_{1}$. $C_{d}$ basis indicated the only appreciable differences noticed were in the $C_{\text {f }}$ predictions for the higher angles-of-attack. Packing points in near the ice surface (both along the surface and normal to the surface) resulted in delayed stall prediction and thus higher predicted $C_{1}$. This is attributed to improved computations of vorticity generation and resolution of the boundary layer growth.

The results of this initial study failed to show any significant differences when using grids from the GRAPE and HYPGRID codes. These studies are continuing. Also ice shape sensitivity studies are being conducted with the IBL code. Since the IBL analysis combines potential flow and boundary layer routines, no grid generation is required. These studies are aimed at determining how detailed the input ice shape must be to yield accurate results from the aerodynamic analysis.

Previous clean airfoil studies 10 have identified that boundary layer transition location can have a significant effect on airfoil performance predictions. A limited study was conducted with the $A R C 2 D$ code to assess the importance of transition location specification for the iced airfoil. Figure 16 shows the results for the computations of the flow about the idealized ice shape previously discussed for two specific transition locations. The forward location corresponded to the tip of the upper horn while the aft location corresponded to the point midway between the separation and reattachment locations. There was no effect on the computed values for lift and drag but a noticeable effect did occur for the velocity profiles in the separated flow zone and the size of the separated flow bubble.

The aft specification of the transition location resulted in a larger bubble with a reattachment point which agreed more closely with the experimental measurements. However, the computations forced a relaminization as the fluid moved 


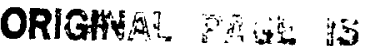 \\ OF POOR QUALITY}

upstream forward of the transition point. Consequently, the magnitude of the reverse flow velocity is overpredicted. For the forward specification of transition, the separated flow zone was completely turbulent and the velocity levels near the surface were in better agreement with the experimental data.

The ARC2D calculations shown in the previous figures were accomplished using a Baldwin-l.omax turbulence model. Recently, investigations have been initiated to look at the effect of alternate turbulence models on iced airfoil flowfield predictions. The initial results of that study are summarized in Fig. 17. Two turbulence models have been used for comparison with the Baldwin-Lomax results: the Johnson-King model (an ordinary differential equation model) and the $k-\varepsilon$ model (a two equation model). A comparison of the leading edge surface pressure distributions shows that no noticeable effect could be seen. All three sets of calculations resulted in a significant overprediction of the suction peak and no prediction of the observed pressure plateau. In addition, all three calculations indicated a smaller separation zone than was measured. The comparison of the predicted velocity profiles in the separation zone as well as the global values of $\mathrm{C}_{1}, \mathrm{C}_{d}$, and $\mathrm{Cmc}_{4}$ also failed to show any significant differences.

These resuits suggest that implementation of a more sophisticated turbulence model in the iced airfoil analyses is not warranted at this time. The additional CPU time required to perform the calculations does not appear to yield any improvement in results over those acquired using a simple algebraic equation turbulence model. Efforts are continuing to look at other algebraic equation models which are avaliable. These results also suggest that a turbulence model "tuned" to handle separated-reattached flows will most likely be required.

\section{Concluding Remarks}

This paper has reviewed the current status of an ongoing NASA activity to develop and validate an airfoll licing analysis capability. The selected results shown indicate that first generation analysis codes exist to predict (1) ice accretion shapes and (2) resultant aerodynamic performance levels. The codes have not as yet been integrated into a single analysis methodology due to the large computer times required to perform the aerodynamic analysis, but this is a desired longer term goal. Work is underway to improve the understanding of the key physics of the ice accretion process so that the ice accretion analysis code can be modified to improve the prediction of ice shapes. Two aerodynamic analysis codes are being evaluated and both show promise for predicting airfoil degradation due to ice accretions. Limitations in the two derodynamic analysis have been identified to include: ice shape description/grid generation, transition speclfication, and turbulence modelling. Efforts are underway to address these deficiencies.

An additional limitation which also must be added to both the ice accretion and aerodynamic analyses is an adequate treatment of the extreme levels of surface roughness which can extst on ice shapes, particularly those formed at warmer temperatures (close to freezing). As already indicated these roughness elements are much different than the classical sand grain roughness elements used in wind tunnel testing. It is felt that these roughness elements must be modelled since they can have a significant effect on the boundary layer growth and thus on heat transfer rates and aerodynamic degradation.

A validated airfoil icing analys is methodology will provide a most useful computational tool to the icing community which can be used for a number of purposes. The methodology will also provide the basis for developing a threedimensional icing analysis methodology to handle geometries such as swept wing configurations. Figure 18 suggests the distinct three-dimensional character that ice accretion shapes can acquire for near freezing temperature conditions. Currentiy efforts are underway to evaluate various three dimensional Navier-stokes codes for possible application to the three-dimensional icing problem. Also, a three-dimensional version of the interactive boundary layer code is under development and wlll be employed. An experimental program has been initiated to measure degradation of wing aerodynamic performance due to a known ice shape. Tests will be conducted for both straight and swept wing configurations. Detailed flowfield measurements will be made using techniques similar to those used during the airfoil icing experiments.

Clearly, the analysis of airfoil icing is a difficult problem for the three-dimensional methods. The three-dimensional problem will provide a much greater challenge to the icing analys is community. The development of such a capability will allow evaluation of civil and military aircraft configurations performance in icing conditions. Such an analysis capability is considered to be valuable to the aerospace community and is a desired end goal of the NASA atreraft icing analysis program.

\section{References}

1. Shaw, R.J.: Progress Toward the Devleopment of an Aircraft Icing Analysis Capability. AIAA Paper 84-0105, Jan. 1984. (NASA TM-83562).

2. Papadakis, M., et al.: An Experimental Method for Measuring Droplet Impingement Efficiency on Two and Three Dimensional Blades. AIAA Paper 86-0406, Jan. 1986.

3. White, F.M.: Viscous Fluid Flow. McGraw-Hill, 1974, pp. 327-329.

4. Kays. W.M.; and Crawford, M.E.: Convective Heat and Mass Transfer. Second Edition, McGraw-HIll. NY, 1980, p. 132.

5. Van Fossen, G.J., et al.: Heat Transfer Distributions Around Nominal Ice Accretion Shapes formed on a Cylinder in the NASA Lewis Icing Research Tunnel. AIAA Paper 84-0017. Jan. 1984. (NASA TM-83557).

6. Olsen, W.; and Walter. E.: Experimental Evidence for Modifying the Current Physical Model for Ice Accretion on Aircraft Surfaces. NASA TM-87184, 1986. 


\section{ORICHAL PRGE IS \\ OF POOR QUALITY}

7. Pulliam, T.H.: Euler and Thin-Layer NavierStokes Codes: ARC2D, ARC3D. Notes for Computational Fluid Dynamics User's Workshop. The University of Tennessee Space Institute, Tullahoma, TN, 1984.

8. Cebeci, T: Effects of Environmentally Imposed Roughness on Airfoil Performance. NASA CR-179639, 1987.
9. Bragg, M.B.: An Experimental Study of the Aerodynamics of a NACA 0012 Airfoil with Simulated Glaze Ice Accretion. NASA CR-179571, 1987.

10. Cebeci, T.; and Whitelaw, J.H.: Calculation Methods for Aerodynamic Flows - A Review. Numerical and Physical Aspects of Aerodynamic Flows III, T. Cebeci, ed., Springer-Verlag, 1986, pp. 1-22.

11. Wu, 3.; Turner, I.; and Wang, C.: Theoretical and Numerical Studies of Oscillating Airfoils. AIAA Paper 89-0021, Jan. 1989.

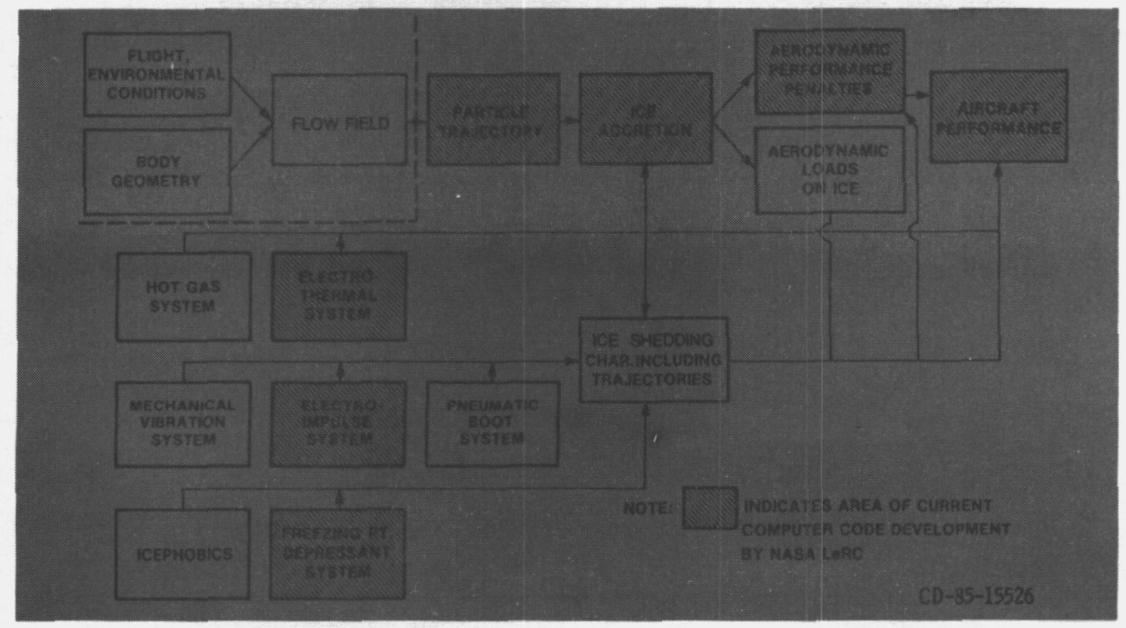

FIGURE 1. - AIRCRAFT ICING ANALYSIS METHODOLOGY. 
ORIGINAL PAGE 15
OF POOR QUALITY

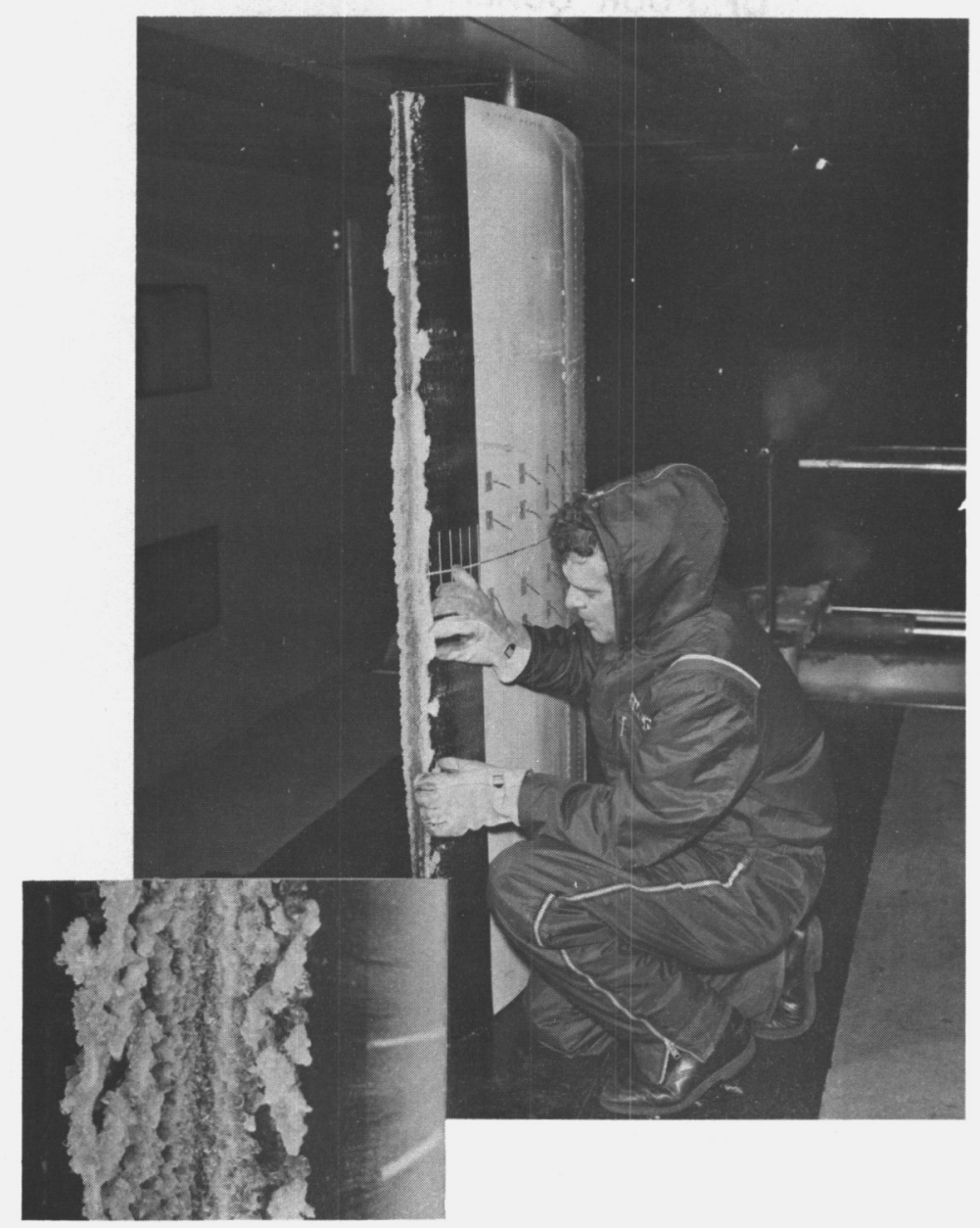

FIGURE 2. - THE AIRFOIL ICING PROBLEM.

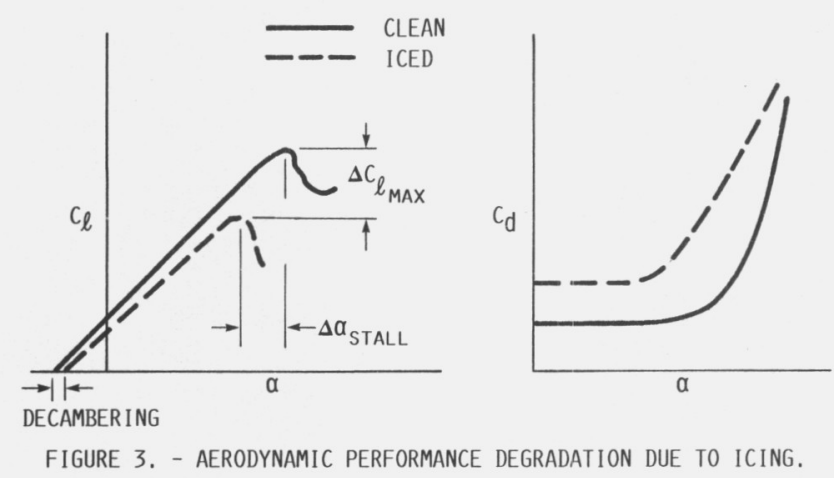




\section{ORIGANAL PAGE IS \\ OF POOR QUALITY}
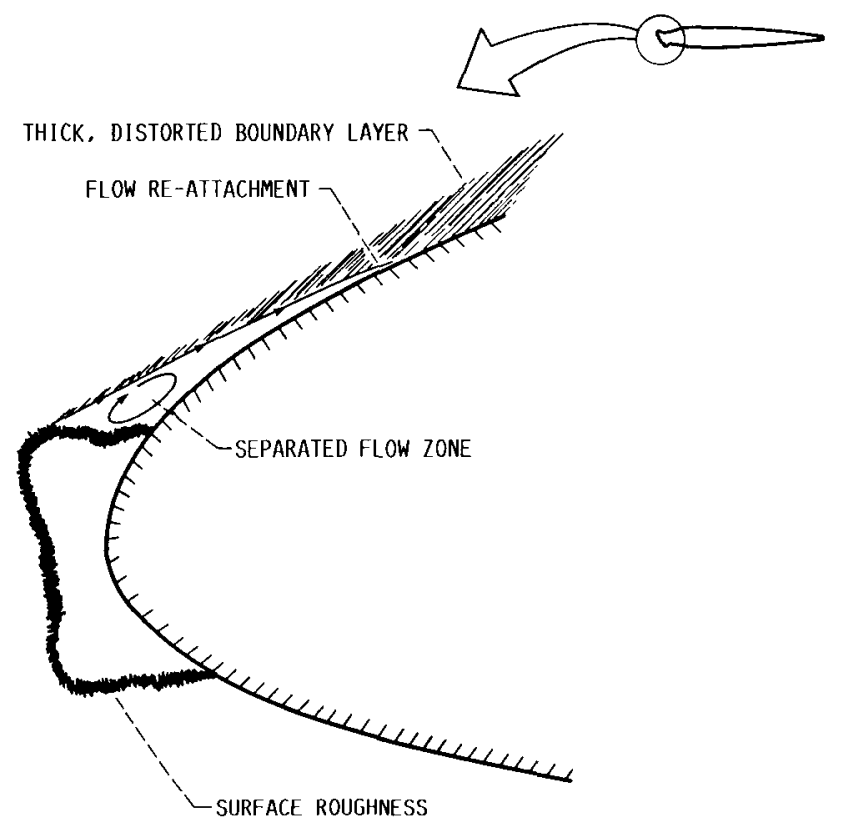

FIGURE 4. - KEY ASPECTS OF AIRFOIL ICING.

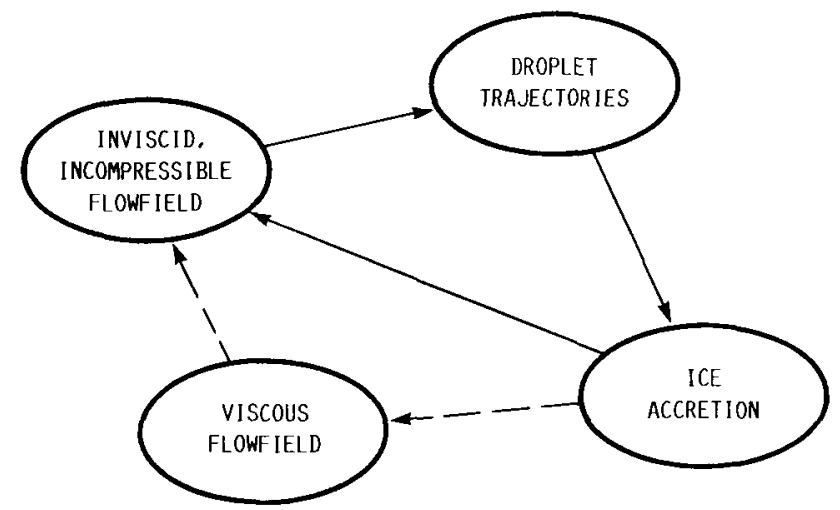

FIGURE 5. - STEPS IN AIRFOIL ICING ANALYSIS METHODOLOGY. 


\section{ORIGHFI PAGE IS \\ OF POOR QUALTTY}
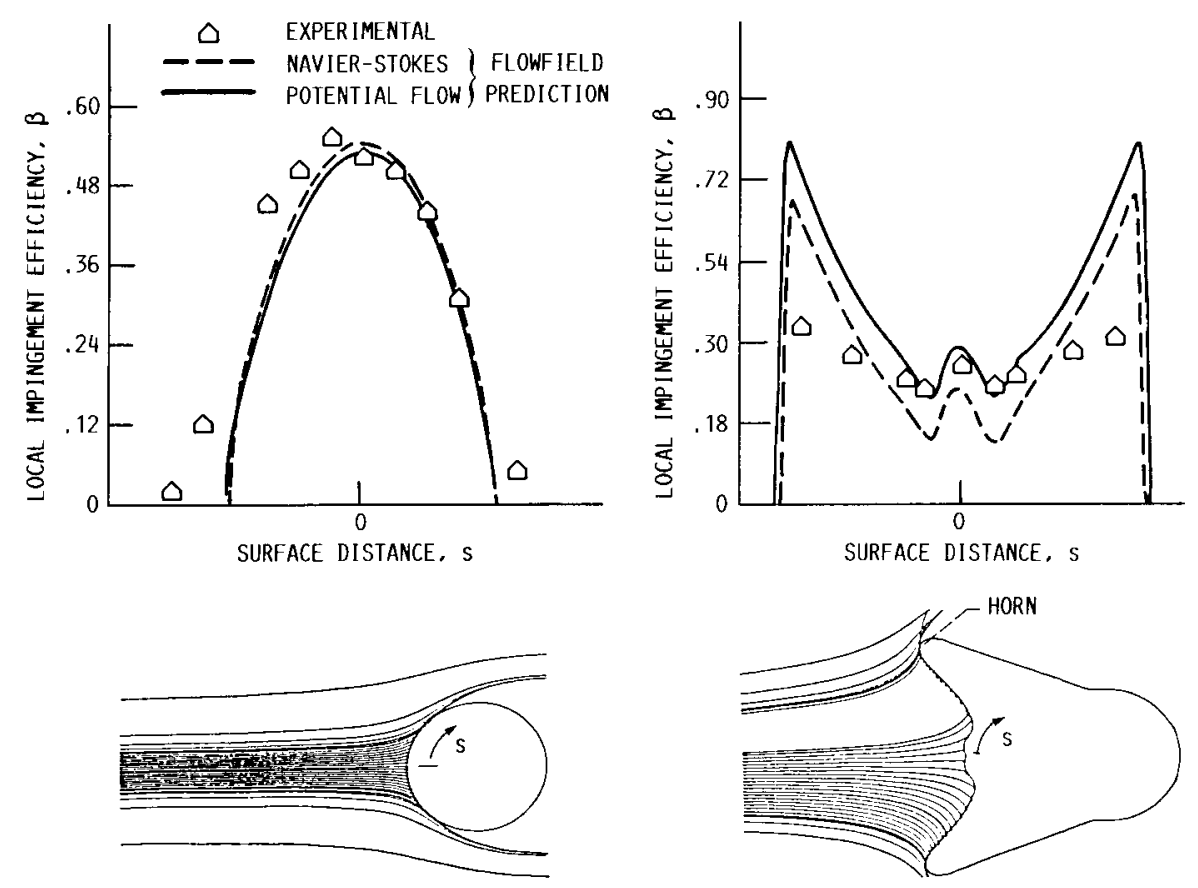

(a) CLEAN CYLINDER.

(b) "ICED" CYL INDER.

FIGURE 6. - COLLECTION EFFICIENCY COMPARISONS.

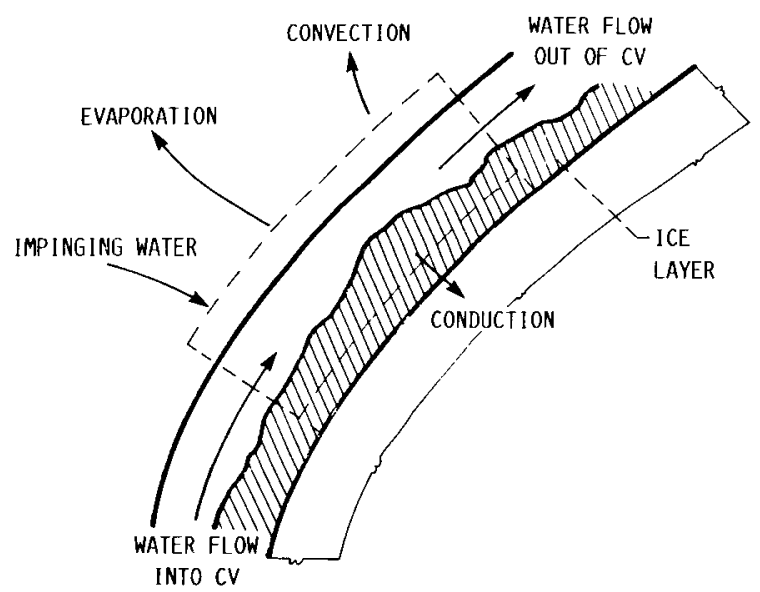

FIGISRE 7. - CONTROL VOLUME ANALYSIS OF ICE ACCRETION PROCESS. 


\section{ORIGINAL PAGE IS \\ OF POOR QUALITY}

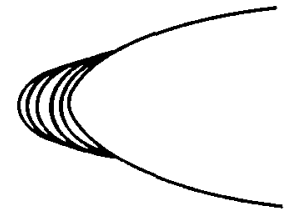

CALCULATED

$L W C=1.02 \mathrm{GM} / \mathrm{M}^{3}$

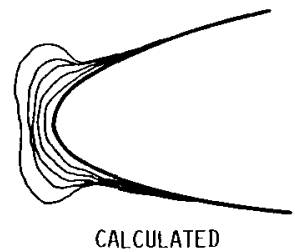

$L W C=1.20 \mathrm{GM} / \mathrm{M}^{3}$

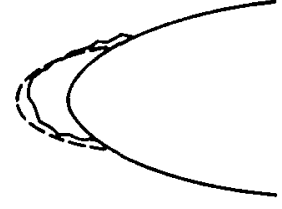

COMPARISON

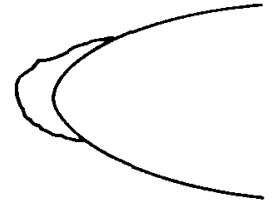

EXPER IMENTAL

$\mathrm{T}_{\infty}=-26^{\mathrm{o}} \mathrm{C}$

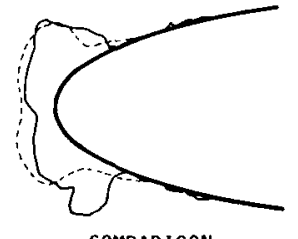

COMPARISON

MVD $=20 \mu M$

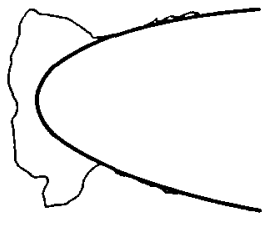

EXPERIMENTAL

$\mathrm{T}_{\infty}=-11^{\mathrm{O}} \mathrm{C}$

FIGURE 8. - COMPARISON OF ICE SHAPE PREDICTIONS WITH AIRFOIL ICING DATA.

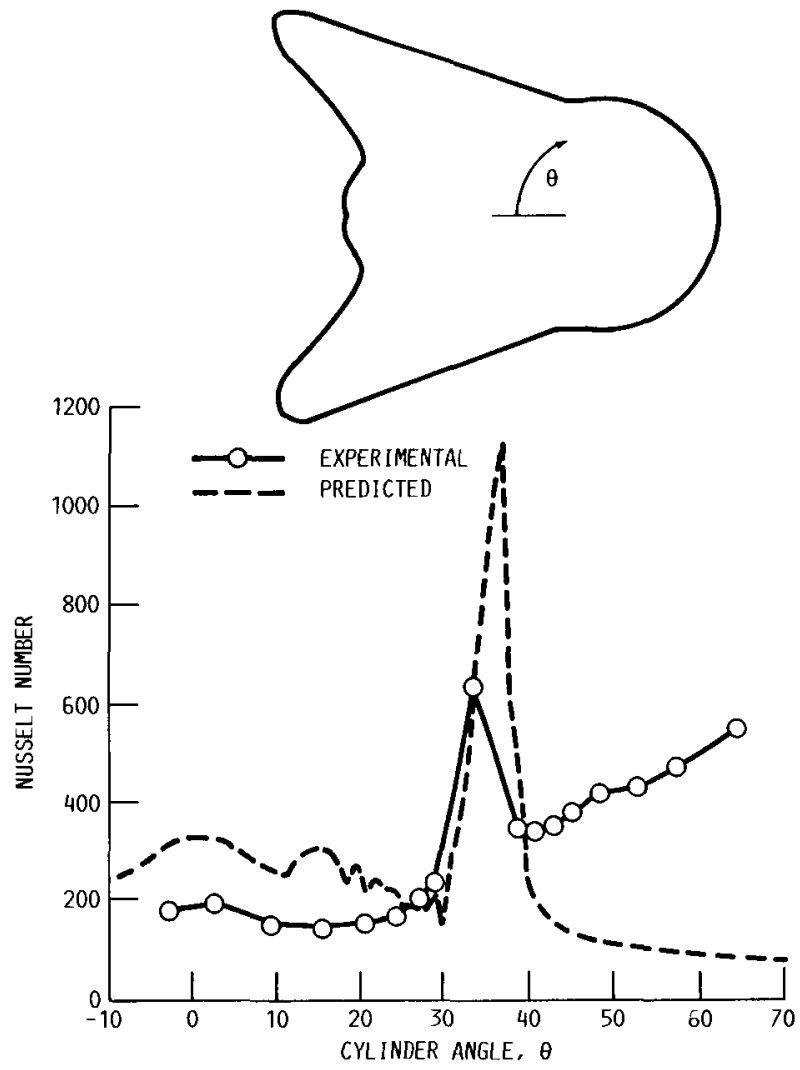

FIGURE 9. - COMPARISON OF CALCULATED AND MEASURED HEAT TRANSFER COEFFICIENTS ON SMOOTH SURFACE "ICED" CYLINDER MODEL.

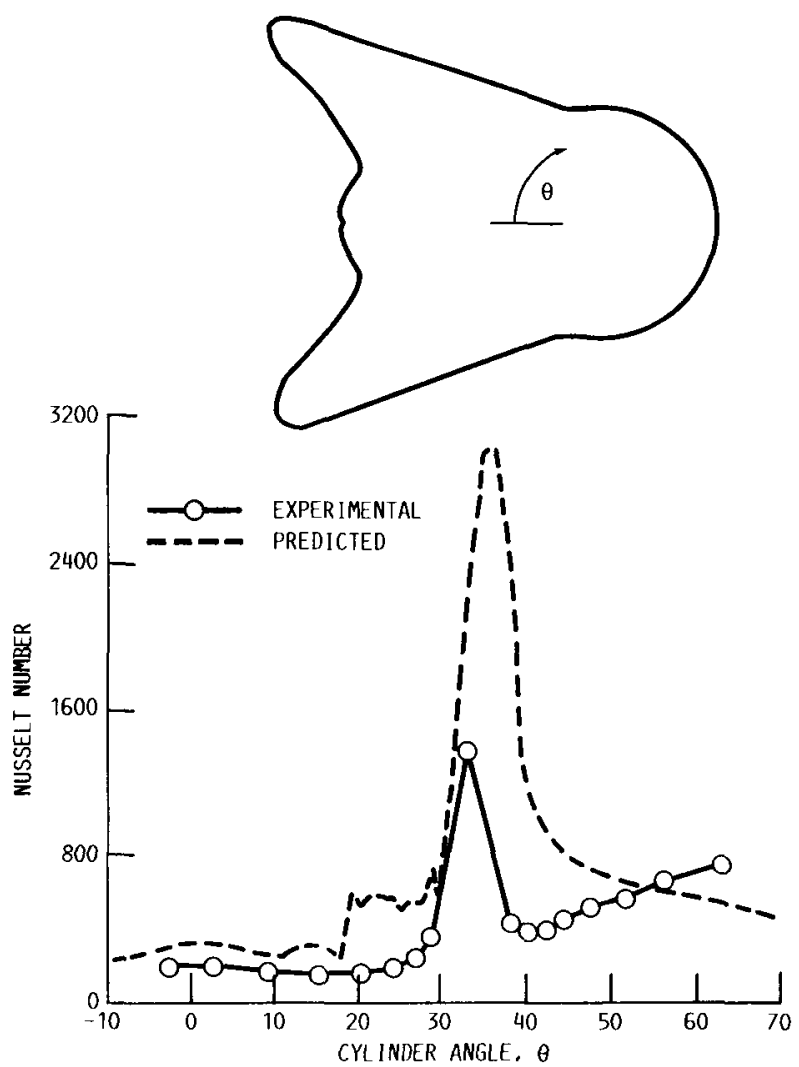

FIGURE 10. - COMPARISON OF CALCULATED AND MEASURED HEAT TRANSFER COEFFICIENTS ON ROUGH SURFACE "ICED" CYLINDER MODEL. 
ORIGINAL PAGE IS

OF POOR QUALITY
ZONE B

LARGE SURFACE ROUGHNESS

NO WATER FLOW

ZONE A

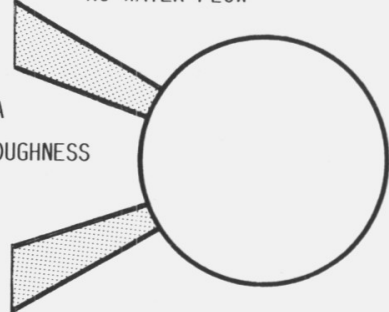

VARYING ROUGHNESS

FIGURE 11. - MULTIZONE MODEL OF ICE ACCRETION PROCESS.

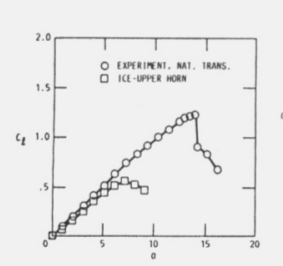

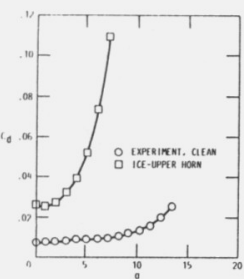

FORCE AND MOMENT DATA
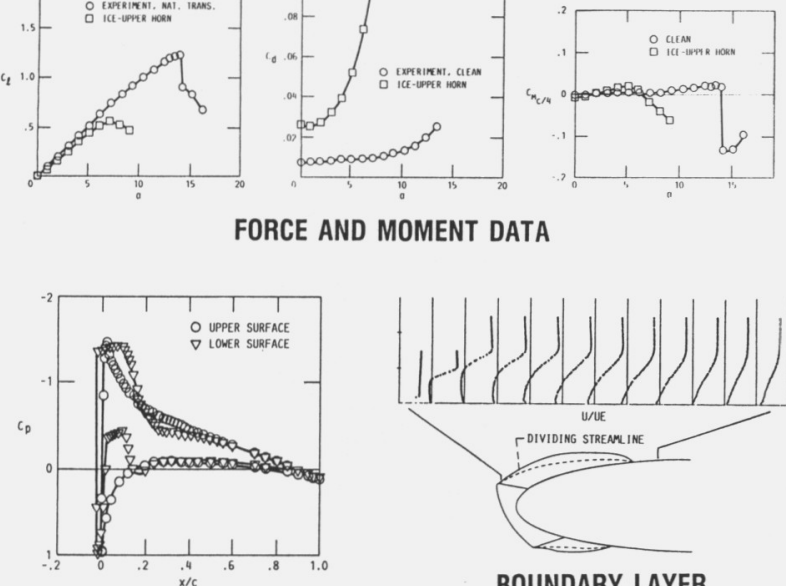

DETAILED SURFACE PRESSURES

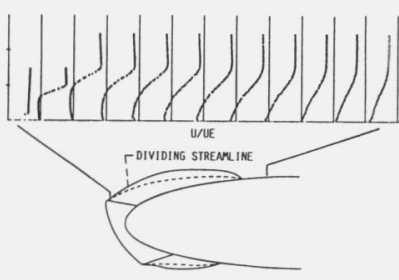

BOUNDARY LAYER

PROFILES

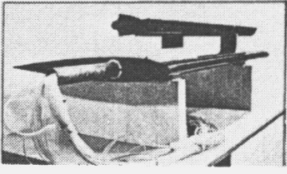

NACA 0012 MODEL

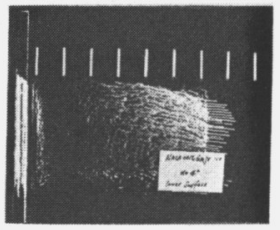

FLOW VISUALIZATION

FIGURE 12. - CODE VALIDATION DATA BASE FOR ICED AIRFOIL PERFORMANCE.
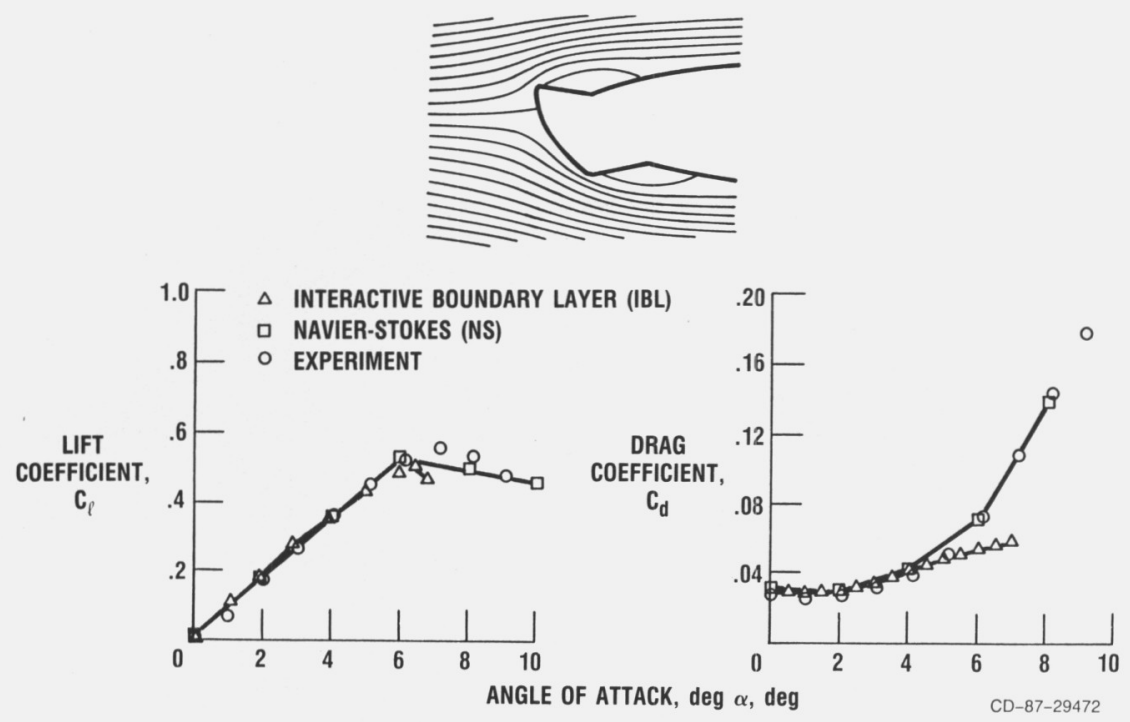

FIGURE 13. - COMPARISON OF ICED AIRFOIL CODE PREDICTIONS WITH EXPERIMENTAL MEASUREMENTS 


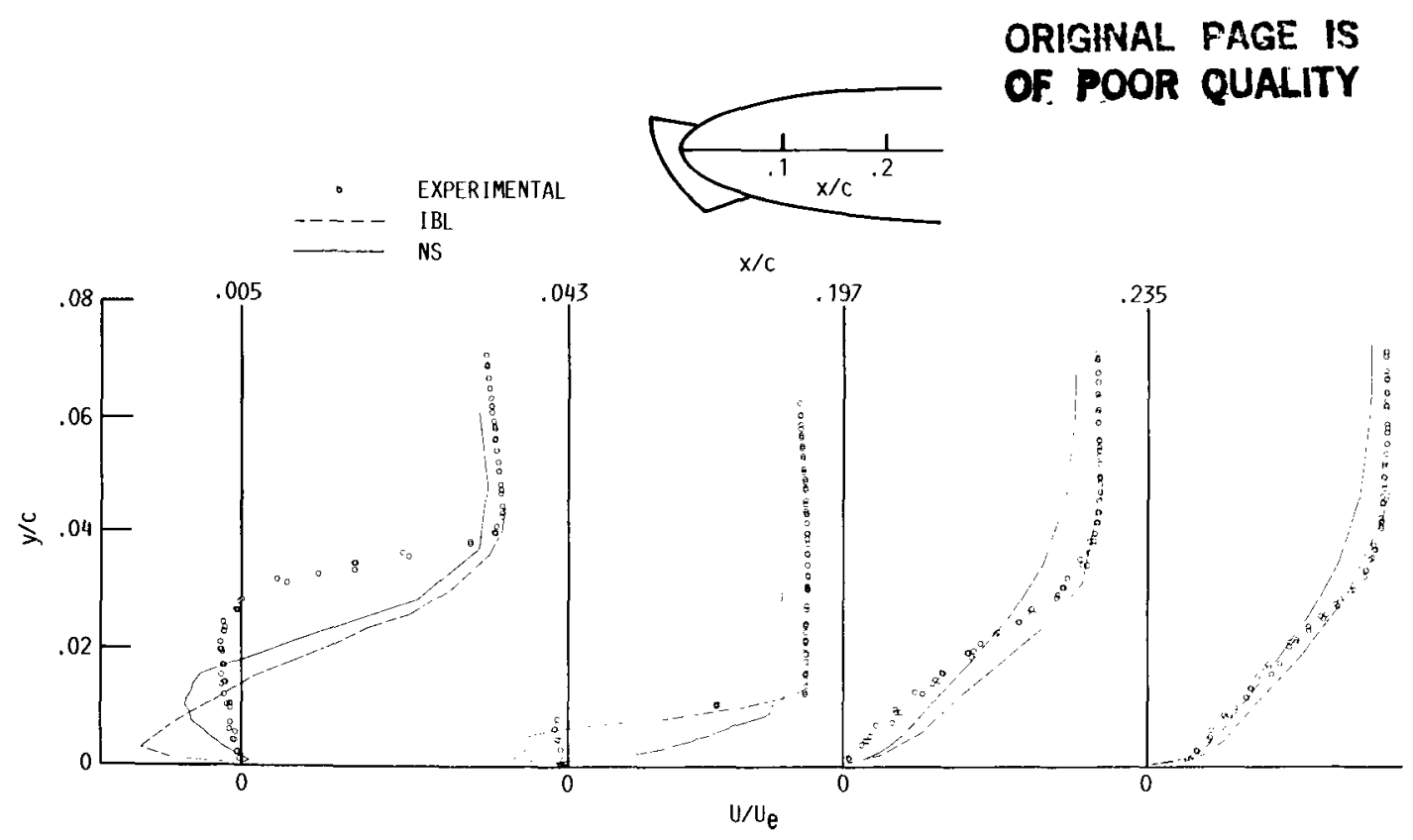

FIGURE 14. - PROFILES OF MEAN VELOCITY FOR "ICED" NACA 0012 AIRFOIL, $a=4^{\circ}$.
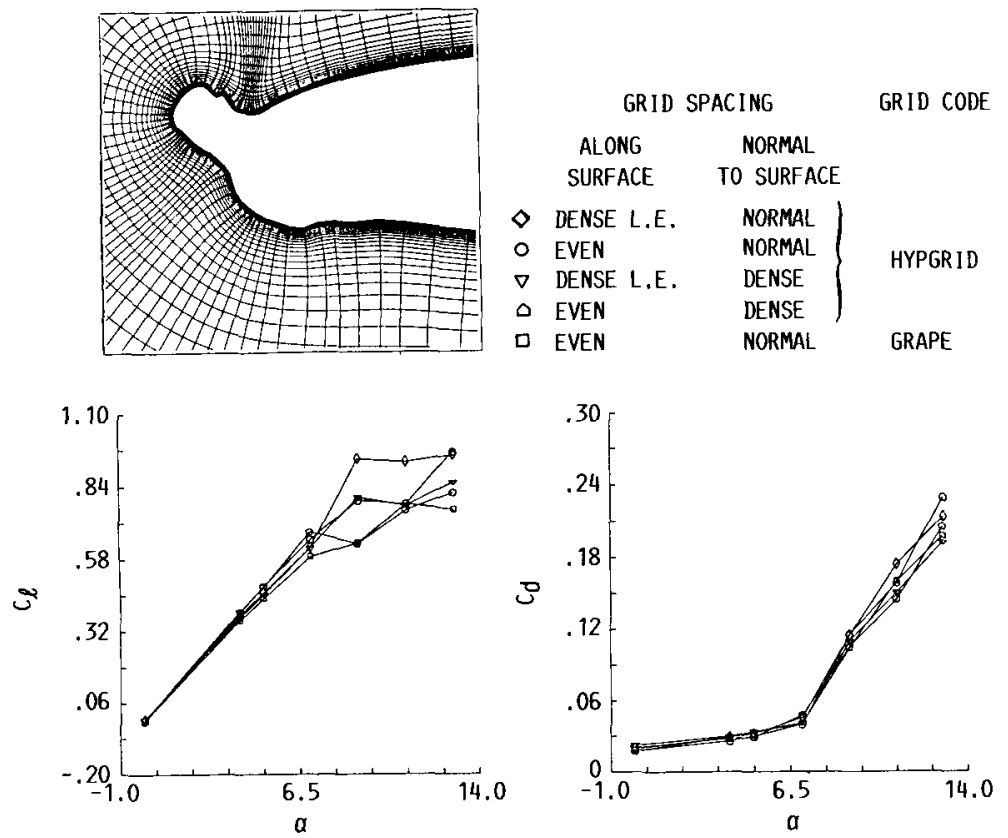

FIGURE 15. - RESULTS OF GRID GENERATION STUDY. 

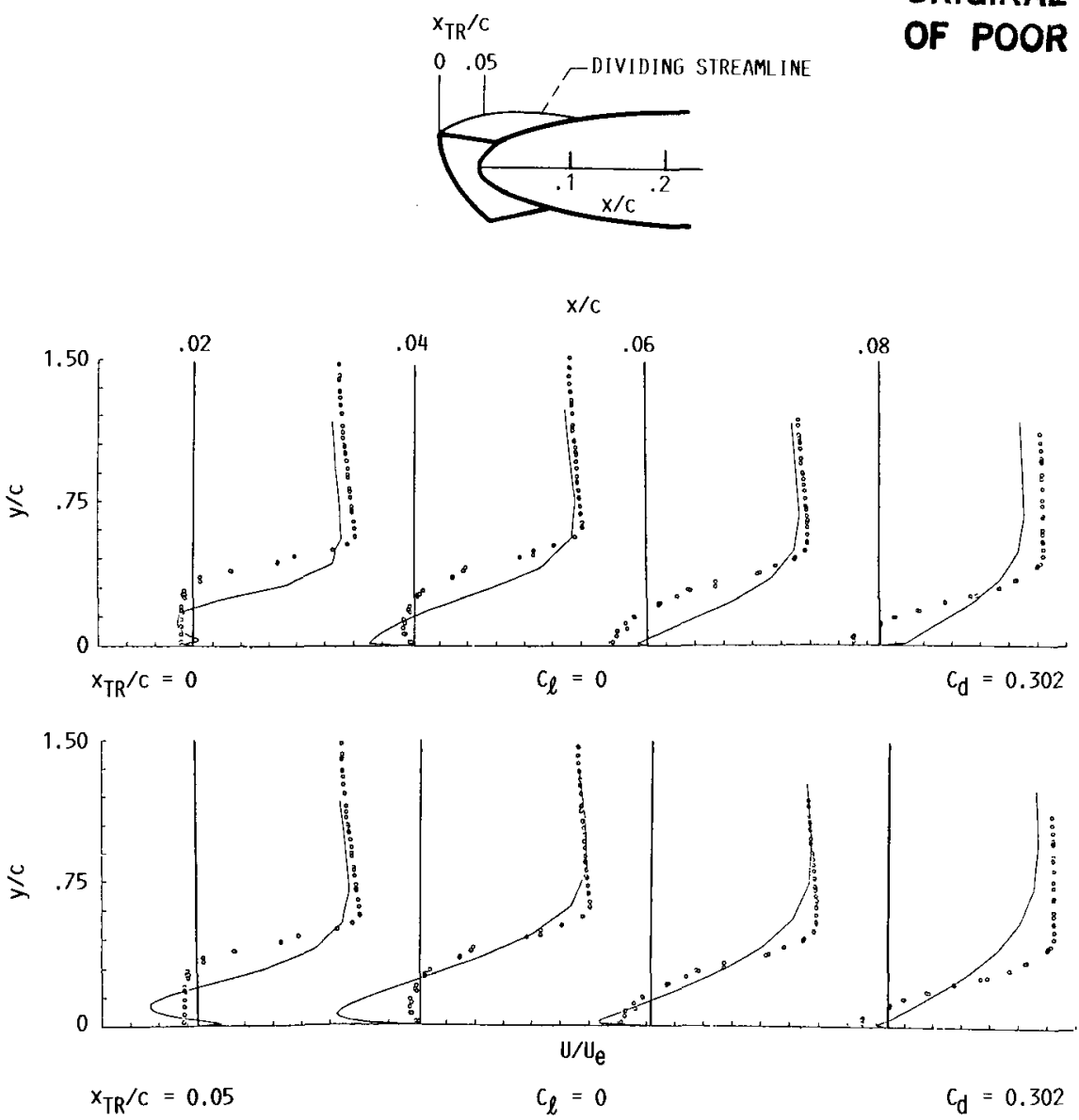

FIGURE 16. - EFFECT OF BOUNDARY LAYER TRANSITION SPECIFICATION IN NAVIER-STOKES PREDICTED VELOCITY PROFILES IN SEPARATION-REATTACHMENT ZONE, $\alpha=0$.
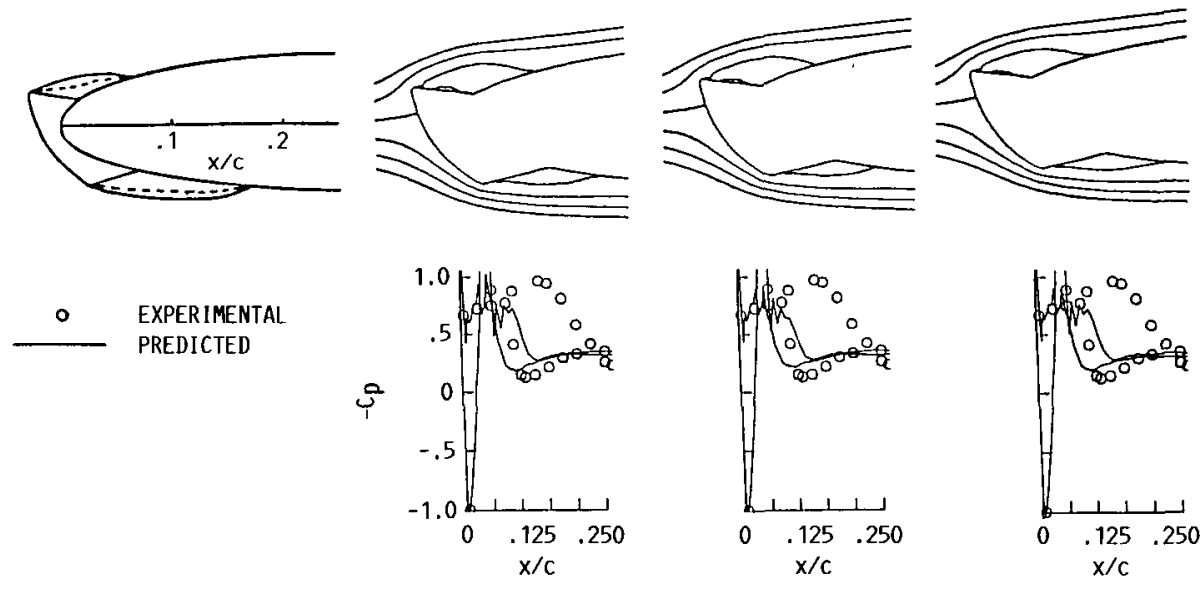

BALDWIN-LOMAX

MODEL
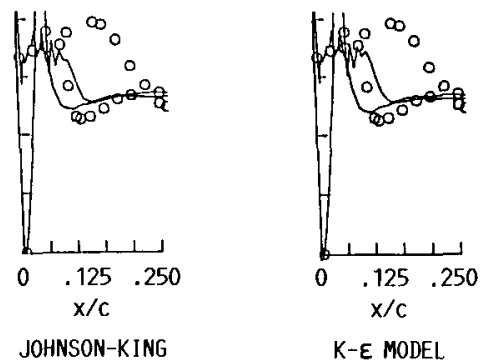

FIGURE 17. - EFFECT OF TURBULENCE MODEL ON NAVIEP-STOKES PREDICTIONS OF LEADING EDGE PRESSURE DISTRIBUTIONS, $\alpha=0^{\circ}$ 


\section{ORIGHNAL PAGE IS OF POOR QUALITY}

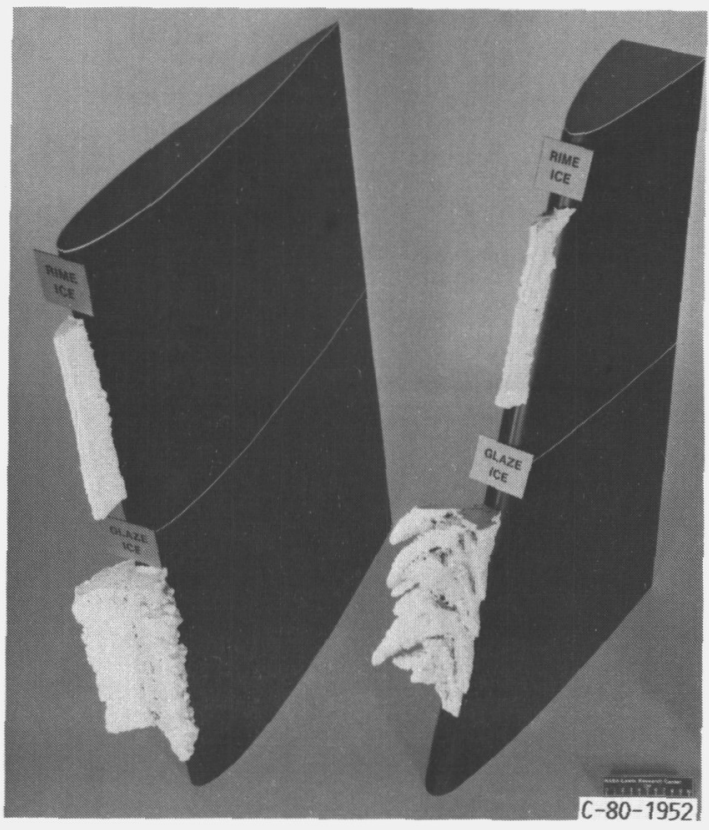

FIGURE 18. - THE EFFECT OF WING SWEEP ON ICE ACCRETION CHARACTERISTICS. 


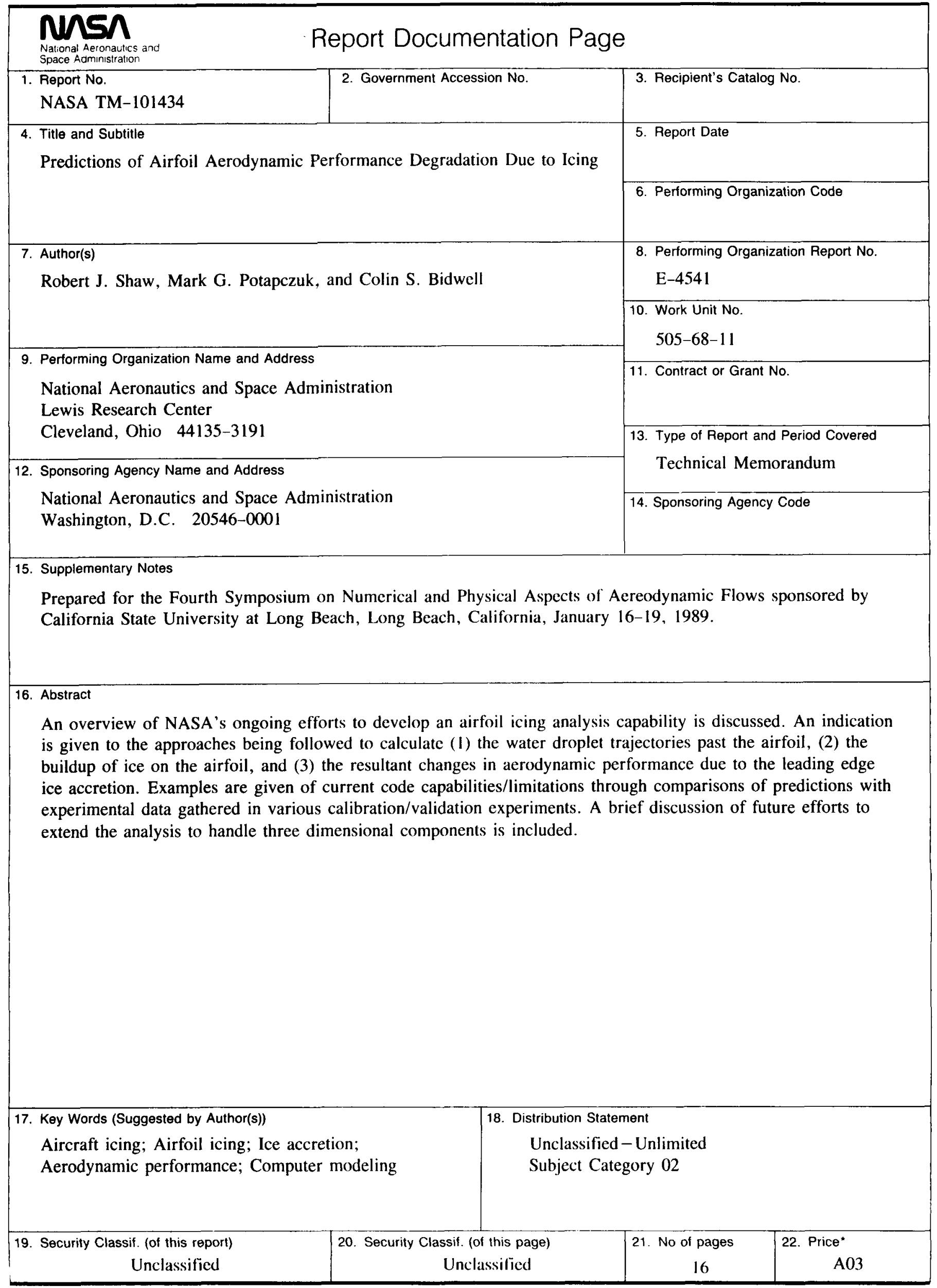

